\title{
Early Indian haematopoietic drugs in the light of their history and therapy
}

\author{
By S. Mahdihassan
}

If we try to learn which has become the foremost simple drug in ancient Greek Medicine and who was its discoverer we shall get no answer. But the same questions put to Indian medicine will reveal ephedra to be the herb yielding Soma juice as the drink of immortality and its earliest user was the aged ascetic. Altogether Indian medicine is not only definite in its character but also unique. Medicine everywhere else is the art of healing diseases and is clearly so with Hippocrates. But the corresponding master of Indian medicine, Charaka ${ }^{1}$, classifies "medicine (as) of two kinds: one promotive of vigour in the healthy (though aged), the other destructive disease in the ailing". In his Codex, Charaka clearly admits rejuvenation as possible and calls this branch of medicine Rasayana, and it has the preference over the art of healing. He was the court physician of the Scythian king Kanishka, who ruled from Peshawar about 100 A.D. which thus assigns to Charaka the same date. Obviously his Codex was a compilation so that the system of medicine giving preference to rejuvenation has a much earlier history. Such sources of information however would be Vedic literature, religious in character, and not free from mythology. It is however possible to trace the two divisions of medicine in Charaka to corresponding two kinds of prayers in Atharva Veda, to be dated about 1500 B.C., as has been explained in an earlier publication $^{2}$. Briefly the founder of Indian medicine figures as the aged exile whose life being full of "grief and woes", needed, in the first instance, an energizer and this he discovered as ephedra, a hardy plant which crushed between stones with added water produced the juice Soma. The realistic basis of such an agency however was its energizing effect. This requires distinguishing an energizer from drugs classed as intoxicants, narcotics and hallucinogens. An energizer enables its consumer to over-exert himself, retain his normal wits, remove depression being positively euphoriant. Soma is no longer in use, but its role in the life of the ascetic can be judged from what is known about other energizers particularly Cathaedulis, the Khat of Yemeni Arabs. The bale a collie can not lift, but after chewing fresh leaves of this plant, he feels the weight no more than a feather on his back. Being euphoriant the public of Yemen has also learnt to enjoy it regularly after the day's work. The active principle of ephedra is ephedrine, and 
Meyers ${ }^{3}$ and co-authors inform that "such drugs cause in addition a pleasurable subjective response because of their euphoriant effect". It is antisomnolent and a habit-former. We can now visualize how the solitary old exile taking Soma was physically and mentally able to ransack the resources of the forest for his daily ration as tubers, vegetable plants and wild fruits. Without an energizer he could hardly be his own grocer, cook, doctor and nurse. Because of its euphoriant effect the Aryan nomads, whose life was also badly in need of comforts, took to it with a vengeance. Just as ordinary kitchen fire, being indispensable to a nomad, became Agni, the god of fire, ephedra equally indispensable to the Aryan ascetic because Soma, god of vegetation and also god of moon since it was believed that the choicest herbs grow on the moon. The identity of ephedra as Soma by Charaka $(1 ; 496)$ consists in his writing that "the sovereign herb known as Soma has fifteen joints for knots". Several plants have been imagined as representing Soma but only ephedra has needed or jointed stems, a feature incidentally depicted on a piece of sculpture of Gandhara art of about 300 A.D. and illustrated in an earlier communication ${ }^{4}$.

However ephedra is not found in the plains of Punjab where the Aryans first settled themselves in India. They tried to substitute Soma by other drugs which were given the generic name Rasayana, which at first were selected herbs, next herbo-metallic complexes and finally herbo-mercurials. The initial property attributed to Soma-Rasa, the Soma-juice, was to be maintained also in Rasayana. Now the drug of rejuvenation cannot be translated by any word of Greek or Latin origin, and Monier-Williams ${ }^{5}$ translates it as Elixir ${ }^{6}$, which is a Chinese derivate, since the Chinese also had asceticism and drugs claiming to immortalize man.

When we consider Chinese medicine we find two phases of it. It started with herbal-magic exploiting plants. This is obvious, for the Chinese god of immortality emerges from a peach and not from a pill of mercurial. From herbal magic they went over to mineral magic and this produced an impact upon Indian medicines and the latter introduced calcined metals, calcining metals always with herbs. Since herbalism dominated Indian medicine it was believed that the herbs were far more important, and while calcining they merely got rid from the plant its ruffage, whereas its active principle was incorporated into the metal. This again is an unique idea and needs documentation. The Maharaja of Gondal ${ }^{7}$ was a doctor of medicine from Edinburgh. He writes that the ancient Hindus "have described the method of transfering properties of vegetable cures to certain metals which intensify their efficacy and retain it a long time". Briefly an improved class of drug arose clearly as herbo-metallic in constitution. 
We now turn to such drugs which were supposed to promote blood formation in the aged who are notoriously anaemic. If the youth has a pink complexion the aged is relatively yellow. Now the earliest conception of soul was that of blood. Fresh blood is red but after giving rise to warm vapours it leaves a dark residuum as the mere vehicle of soul. Thus Blood was fractionated into Redness as the real active principle which evaporates as Vapours. This equates Blood $=\mathrm{Soul}=$ Redness. Then anything red was the donor of life-essence, the creative principle. The cave dwellers used red ochre internally as the drug of longevity and also smeared it on the remains of the dead to resurrect them. Later on it was discovered that iron, on rusting, becomes red and with sufficient insight it was realized that red ochre itself contains sufficient iron. In the light of such information the importance of iron was realized as a drug rich in life-essence. Charaka $(1 ; 489)$ has a long paragraph entitled "Iron vitalizer". Iron is beaten into thin plates, heated in fire and dipped in extracts of vegetable drugs when "they turn black but should be ground to fire powder". This is mixed with honey and juice of Phyllanthus emblica and saturated with boiled butter. The mixture is placed in an earthen pot and left for a year. Meanwhile it is stirred every month to see that iron reacts fully with the other ingredients. The use of boiled butter is to prevent oxidation. Honey with its glucose and specially fructose is an excellent reducing agent. Above all Phyllanthus emblica is the richest natural source of ascorbic acid which can produce iron-ascorbate in a vehicle rich in antioxidants like honey and butterfat.

The "Vitalizer" to which is assigned the greatest importance is dealt within a paragraph entitled "Simple emblic myrabolan vitalizer". Here is offered the naive suggestion for the patient to "enter a grove of (trees) bearing emblic myrabolans, Phyllanthus emblica". The fruit is "certainly an ambrosia". - "As many fruits as he eats so many milleniums does he live with youth restored." Thus Charaka is at his pitch of eloquence in praising as Simple, or as single drug, Phyllanthus emblica, now known to be exceptionally rich in ascorbic acid. Next he recommends a preparation of reduced iron treated mainly with the fresh extract of the same fruit. Thus we find that both iron and ascorbic acid would be recommended as the drugs of choice in modern therapy of anaemia. 


\section{References}

1 Charaka Samhita (Codex), Vol.V. Published by Gulabkunerva, Ayurvedic Society, Jamnager, India, 1949.

2 Mahdihassan, S., Medicine and alchemy in Indian culture. In: Scientia 108 (1973), p. 858.

3 Meyers, F. H., and others, Review of medical pharmacology. Maruzan Asian Edition 1970, p. 80.

${ }^{4}$ Mahdihassan, S., Soma, in the light of comparative pharmacology, etymology and archeology. In: Janus 61 (1974), p. 91-102.

5 Monier-Williams, Sir M., A Sanskrit-English Dictionary, 1899. The word Rasayana.

${ }^{6}$ Mahdihassan, S., Elixir, its significance and origin. In: Journal of the Asiatic Society of Pakistan, Dacca 6 (1961), p. 39-53.

7 Bhagavat Sinhjee, His Highness, A short history of Aryan medical science, Gondal 1937, p. 137.

\section{Summary}

The earliest recognized Simple in Indian medicine was ephedra discovered by the Aryan ascetic as an energizer. This was exaggerated into a drug of rejuvenation and even of immortality. The juice extracted from ephedra was called Soma-Rasa, the Some Juice. Later on it was replaced by other vegetable drugs called Rasayana, as drugs of rejuvenation. Further come as belonging to the same class, calcined metals, conceived as herbo-metallic preparations, again for treating infirmity of the aged. Among such medicaments came reduced iron and ascorbic acid, the latter through the fruit Phyllanthus emblica. Their use can be justified as being anti-anaemic in the light of modern therapy.

S. Mahdihassan

SD. 34-Block A.

North Nazimabad

Karachi 33 